DOI 10.37882/2500-3682.2021.11.19

\title{
СОЦИАЛЬНАЯ СОСТАВЛЯЮЩАЯ В СТРУКТУРЕ ТЕХНИЧЕСКОЙ ДЕЯТЕЛЬНОСТИ КАК ВОЗМОЖНОСТЬ КОНТРОЛИРУЕМОГО ЕЕ РАЗВИТИЯ
}

\section{THE SOCIAL COMPONENT IN THE STRUCTURE OF TECHNICAL ACTIVITY AS AN OPPORTUNITY FOR ITS CONTROLLED DEVELOPMENT}

\section{A. Shustov}

Summary: The object of the study is technical activity. The purpose of the study is to analyze the structural components and specifics of technical activity in order to identify the social aspects of its development and to show the possibility of a controlled direction of its development. This will help to avoid its destructive manifestations in social life.

Keywords: activities, technical activities, technology, norms, values, needs, subject to technical activities, subject to technical activities.

\author{
Шустов Александр Федорович \\ Д.ф.н., профрессор, Брянский государственный \\ аграрный университет \\ shustovaf@mail.ru
}

Аннотация: Объектом исследования является техническая деятельность. Задача исследования проанализировать структурные компоненты и специфику технической деятельности с целью выявления социальных аспектов ее развития и показать возможность контролируемой направленности ее развития. Что позволит избежать деструктивных ее проявлений в социальной жизни.

Ключевые слова: деятельность, техническая деятельность, техника, нормы, ценности, потребности, субъект технической деятельности, объект технической деятельности.

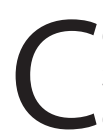

овременный этап развития общества характеризуется проникновением техники во все сферы как социальной жизни человека, так в мир природы. И такое тотальное вторжение носит порой неоднозначный характер, наряду с положительным, прогрессивным ее влиянием, способствующим развитию, как общества, так и человека. Имеется и вторая сторона, которая характеризуется деструктивным проявлением техники, что выражается в экологической проблематике, подавлении культуры и различные формы зависимости от нее человека. Встает и все более разрастается проблема о возможности контролируемого развития технической деятельности

В данной статье мы рассмотрим природу и структуру технической деятельности, с выявления механизмов ее контролируемого развития Деятельность - это некая активность система поступков, которая направлена на целесообразное изменение природных и социальных объектов. Смысл человеческой деятельности состоит в хранении, накоплении и передачи социально значимой информации. На определенном этапе человеческой истории потребовалось создать механизм внегенетической передачи социально значимой информации, с целью расширения социальных возможностей человека в различных областях культуры и деятельности.

В структуру любой человеческой деятельности входят основные компоненты: целенаправленность, преобразовательный, ценностно-нормативный. Рассмотрим эти выделенные компоненты и выделим их специфику в структуре технической деятельности.

Любая человеческая деятельность носит целенаправленный характер это и является ее отличительной чертой. Человеческая деятельность отличается продуманностью, предварительным анализом проблемной ситуации, выбором последовательности действий, механизмов и способов её применения. Неотъемлемым атрибутом человеческой деятельности выступает создание мыслительной схемы, проекта, образа в зависимости от поставленной цели и проблемной ситуации. Идеальное построение действий, мыслительных вариантов и предполагаемых результатов дает возможность выбора цели, последовательности действий различным актам деятельности. Деятельность определяется осознанной целью, поэтому она носит целенаправленный характер, однако сами цели порождаются контекстом человеческого существования, сферой человеческих потребностей, мотивов, идеалов, ценностей. В деятельности осуществляется диалектическое единство субъективных и объективных сторон детерминации.

Поэтому, социальные потребности, мотивы и стимулы показывают, как объективная детерминация реализуется в процессе субъективной технической деятельности и, выступая самим механизмом этой реализации, дает возможность более четко осмыслить конкретный процесс причинной обусловленности технической деятельности. Начальным этапом детерминации вы- 
ступают объективные условия жизни людей, которые порождают у них определенные потребности и цели. В ходе этого механизма происходит переход объективной детерминации в субъективную. Элементами этого механизма выступают: сложный процесс осознание потребностей, определение целей к которым нужно стремиться, разработка программы действий, выбор средств её осуществления.

Идеальная конструкция модели будущей деятельности будет продуктивной, если она несет в себе определенные свойства, которые вырабатываются в процессе исторического становления человека. Это, цель как проект будущей деятельности и её продукт должна быть представлена человеку субъективно, как образ, которым он может свободно оперировать. Продукт деятельности определяется тем, в какой мере идеальная цель, проект воплощает в себе объективные свойства и характеристики предмета. Если в проект заложены недостоверные или неточные знания о действительности, то и результат реализации этого проекта будет отрицательным. Поэтому, чтобы цель как идеальная модель будущей деятельности была продуктивной, она должна выражать существенные характеристики явлений, выявлять их объективные структуры и связи.

Социальные цели, реализующиеся в технической деятельности, выступают механизмом развития не только мира технического, но и служат общественному развитию в целом. Смысл целеполагания в технической деятельности проявляется в создании технических объектов для решения социальных целей, поскольку любая цель реализуется с помощью набора различных средств, а эти средства не существует вне определенной цели. Интересные мысли о механизме целеполагающей деятельности были высказаны ещё Гегелем.

“Разум, - по его меткому замечанию - столь же хитёр, сколь и могуществен. Хитрость состоит вообще в опосредующей деятельности, которая, позволив, объектам действовать друг на друга соответственно их природе и истощать себя в этом воздействии, не вмешиваясь вместе с тем непосредственно в этот процесс, все же осуществляет свою собственную цель"[1, с. 397]. Он впервые показал непростой характер детерминации технического развития в ходе, которого в технических средствах противоречивым образом воплощаются две формы объективного процесса - природного и социального.

Субъект технической деятельности, воплощает свои знания, способности, потребности в созданных им технических объектах, реализует в них свою цель. Специфика технической деятельности определяется тем, что результат этой деятельности предполагает разработку новых видов технических объектов, средством достижения цели которой она выступает. В силу этого в ней скла- дывается специфическое соотношение между целью и результатом, материальным и идеальным, субъектом и объектом. В других формах деятельности реализованная цель безразлична к последующему его функционированию. Воплотившись в материальном объекте, она исчезает. В продуктах технической деятельности реализованная цель выступает основанием для ее последующего развития. Поэтому технический объект как целесообразный феномен является связывающим звеном между предшествующей деятельностью по созданию техники и будущей деятельности по ее применению.

Смысл деятельности по использованию техники, как продукта предшествующего труда состоит в первую очередь в том, чтобы была раскрыта цель, заключенная в ней ранее, что позволяет сохранить историческую связь поколений субъектов технической деятельности, а также традицию единства между прошлыми и современными видами и формами деятельности.

Преобразовательный аспект. Любая человеческая деятельность направлена на преобразование природных и социальных объектов вне субъекта деятельности, в результате чего выступает нечто новое не существовавшее ранее. Каган М.С. отмечает: "Для преобразовательной деятельности как таковой безразлично кто именно является преобразующим субъектом, что именно является преобразующим объектом, в какой конкретной форме и на каком уровне осуществляется само это преобразование" $[2$, с. 54]

Посредством техники раскрываются преобразовательные возможности человека, благодаря которым он способен изменять мир, т.е. она участвует в развитии преобразовательных способностей субъекта, усиливает их, что позволяет раскрывать новые «потаенности бытия». Это позволяет субъекту деятельности раскрывать сущностные моменты мира природы с помощью создания новых технических средств. В результате этой деятельности происходит преобразование природного вещества в технические объекты, в которых снимается природная форма вещества, от своего естественного состояния. Т.е. мир естественного, трансформируется в мир искусственного.

В ходе преобразования естественные объекты и явления приобретают новые качества, теперь они управляются не только природными закономерностями, но и зависимых от воли человека социальных закономерностей порождаемых социокультурной системой.

Ценностно-нормативный аспект. Ценности - это необходимая характеристика человеческой деятельности, существенный момент её социальной природы. Они присущи как субъекту деятельности, так и результату деятельности в целом. Как уже, отмечалось выше, 
деятельность представляет собой механизм передачи социально значимой информации. В этом механизме раскрывается роль техники как социокультурного феномена, вплетенного в механизм социального наследования. Ценностно-нормативный аспект является одним из важнейших в механизме социального наследования. Содержание ценностного отношения задается социальной формой применения техники и культурными установками в целом, что выражается в ценностных установках того или иного субъекта. Понятие "ценностной установки" отражает реальный механизм освоения человеком налично существующих ценностей, механизм связи между ценностным объектом и интересами и потребностями субъекта.

Успешное функционирование технических объектов зависит от их ориентированности на экономические показатели и культурные ценности. Это проявляется в социальном заказе общества к деятельным установкам по созданию новых технических объектов и реконструкции уже существующих. Поэтому необходима комплексная социальная оценка их разнообразных функциональных характеристик. Социальная оценка объектов технической деятельности должна начинаться с определения базовых технических потребностей общества, средством реализации которых являются технические системы [3 с. 3].

И только после всесторонней социальной оценки создаваемых проектов можно в полном объёме формировать технические задачи, технические идеи, технические решения, которые закладываются в развитие технологии, понимаемой как способ оптимальной организации технической деятельности

Технический объект в ходе технологического взаимодействии позволяет изменять возможности функционирования данной технологии. Поэтому в технологии осуществляется поиск оптимального функционирования технической деятельности.

В данной статье, в нашу задачу не входит поиск смысловых оттенков в понимании понятий «техника» и «технология», отметим лишь, что общим для них является преобразовательная деятельность человека, и все они являются объектами технической деятельности. Т.к. она в широком смысле слова означает не только создание, но и использование техники. Т.е. в неё входят исследование, проектирование, изготовление и эксплуатация техники.

Благодаря технической деятельности, человек создал новую реальность, положив начало отсчету социального времени. Способность человека создавать разнообразные орудия и средства труда, приспосабливать одни силы для борьбы с другими и выделили его из животного мира и явились решающим фактором выживания человека

С развитием технической деятельности естественный отбор стал оказывать второстепенное влияние на изменение человеческого организма. Ему теперь не требовалось перестраиваться биологически, достаточно было изменить технологию. Техническая деятельность выступает как глубинный архитип в сознании человека деятельного "Homo faber". Способность создавать искусственные объекты лежит в самой природе человека, об этом пишут многие философы. “Природа человека - это его искусственность" - писал К. Ясперс [4 с. 81]. Э. Кассирер рассуждает о неком законе естественной искусственности [5, с. 14], применительно к человеку и плодам его деятельности.

Характерной особенностью технической деятельности является создание искусственных объектов и поддержание их в функциональном состоянии, т.е. таких объектов, которые без человека в природе не встречаются, которые созданы человеком и функционируют благодаря его усилиям. В деятельности человека можно выделить объектную и субъектную стороны. Для того чтобы прояснить возможность контролируемого развития технической деятельности методологически важно кратко остановиться на характеристиках субъекта и объекта её составляющих.

Целеполагающим элементом технической деятельности является субъект. Само понятие "субъект" фиксирует активность индивида по отношению к объекту, целенаправленность его интереса и действий. Структурной организацией субъекта может выступать индивид, так и социальная группа. Субъект выступает не только целеполагающим существом, он носитель определенного уровня знаний, образованности, ориентирующийся на те или иные идеалы и нормы культуры. Когда речь идет о коллективном субъекте, то кроме общей цели он характеризуется и общими социокультурными характеристиками.

Духовная ориентация является неотъемлемой характеристикой субъекта технической деятельности, а значит, тесно связана с ценностями и нормами культуры и ею определяются.

Субъект технической деятельности является носителем социальных норм, культурных ценностей, технологических компетенций, которые проявляются в новых формах технической деятельности и это позволяет функционировать механизму социальной передачи информации и развитию самого субъекта технической деятельности. Субъект технической деятельности содержит в себе технические способности, потребности и знания. При создании технических объектов он использует есте- 
ственнонаучные, технические знания, а также учитывает этические и эстетические ценности культуры.

Объект технической деятельности есть результат превращения природных образований в искусственные материальные образования. Внутренняя структура объекта технической деятельности представлена набором предметов, поставленных в определенные отношения и взаимодействия друг с другом согласно целям деятельности. Поставленность здесь следует понимать в особом смысле, который развит в трудах М. Хайдеггера: "Поставом мы зовем собирающее начало той установки, которая ставит, т.е. заставляет человека выводить действительное из его потаенности способом поставления его как состоящего в наличии. Поставом называется тот способ раскрытия потаенности, который правит существом современной техники, сам не являясь ничем техническим".[6 с.55]

Понятие "технический объект" фиксирует не только наиболее важные стороны технических устройств, технических материалов и технологических взаимодействий. Оно позволяет выделить сферу объективной реальности, противостоящую субъекту в его технической деятельности. Технический объект - это то, на что направлена техническая деятельность, что противостоит познавательной и преобразующей деятельности субъекта. Технический объект содержит в себе две ипостаси: природную и социальную. Социальная составляющая в техническом объекте говорит об искусственной его природе. Искусственные устройства обладают качеством технического объекта только во взаимодействии с использующим их субъектом, владеющим навыками применения этих устройств для достижения своих целей. Утратив это взаимодействие, предоставленный сам себе технический объект становится одним из предметов внешнего мира. Социальная оценка особенностей технических объектов рассматривается через призму их функционирования. Техническая функция обозначает как привносимый объектом полезный эффект, так и область применения технического средства, поскольку она зависит от характера полезного эффекта.

Процесс формирования технического объекта включает в себя в снятом виде различные виды знаний, практических навыков, эстетических норм. Поскольку все эти составляющие обладают автономностью от мира технического и как сфера деятельности и как объект познания они могут считаться её компонентами.

Технический объект это не просто предмет, обладающий определенными свойствами, а предмет, служащий определенным целям, предмет, предназначенный содействовать их реализации. Объект технической деятельности имеет ряд присущих только ему существенных свойств, которые отличают его от объектов других форм деятельности. В процессе развития технической деятельности искусственные объекты постепенно вытесняют естественные формы. Характер возникновения и развития искусственных образований существенно отличается от естественных, т.к. развитие технических объектов обуславливается не естественной эволюцией, а деятельностью человека основанной на внешней необходимости.

Мир естественного и искусственного не отделены китайской стеной друг от друга, а находятся в пространственно-временном и социо-природном единстве. Развитие технического объекта зависит от всестороннего развития субъекта. Т.е. субъект выступает социальным катализатором развития технического объекта. Из этого можно сделать вывод, что техническое новое это отражение социокультурных, ценностных отношений человека к миру и осознание своего места в мире [7, с.59].

Специфика технической деятельности в том, что она способна пересматривать и совершенствовать лежащие в её основании программы, способна к неограниченному "перепрограмированию". Такое "перепрограмирование" зависит от субъекта технической деятельности и от социокультурного пространства, в которое он включен.

\section{ЛИТЕРАТУРА}

1. Гегель Г.В.Ф. Энциклопедия философских наук: в 3 т. М.: Мысль, 1977. Т. 2. С. 397

2. Каган М.С. Человеческая деятельность: монография. М.:Политиздат, 1974.331 С.54

3. Шустов А.Ф. Социальная оценка развития техники//Вестник Брянской ГСХА № 6.- 2014- С. 3-5.

4. Ясперс К. Истоки истории и ее смысл. Вып.1. М., 1978. С. 81

5. Кассирер Э. Опыт о человеке. Введение в философию человеческой культуры// Проблема человека в западной философии. М: Прогресс, 1988. С.14

6. Хайдеггер М. Вопрос о технике // Новая технократическая волна на Западе. М., 1985. 450 с.

7. Свидерский А.А. Техногенность ценностей современного общества // Проблемы современного антропосоциального познания. Брянск, 2019. С.55-60

(с) Шустов Александр Федорович (shustovaf@mail.ru). 